\title{
STUDY OF DIGITAL CAMERA CALIBRATION ON A FLAT TEST OBJECT
}

\author{
A.V. Govorov*, A.G. Chibunichev, S.B. Makarov \\ Moscow State University of geodesy and cartography (MIIGAiK), 4 , Gorokhovsky pereulok, Moscow, RUSSIA, \\ a_govorov@miigaik.ru, agchib@mail.ru, serj@aport.ru
}

\section{Commission II}

KEY WORDS: calibration, digital camera, flat test object, chessboard

\begin{abstract}
:
The paper presents a method for calibration of digital cameras based on the use of a flat test object. The main distinctive feature of this method is that the camera is fixed and does not change its position in space. A series of images of a flat test object (for example, a chessboard) is taken at various distances and inclination of the test object. One should tilt the test object relative to the image plane in order to avoid ambiguity in solving the problem. All these images are measured separately, and processing is performed together, counting them as one image with common exterior orientation elements. Experimental studies have shown sufficient efficiency of such calibration, which is easily implemented and gives positive results in comparison with the classical calibration of the camera on a spatial test object. The results of experimental studies on real images have shown that proposed calibration method gives the comparable with conventional method accuracy. Thus, it is possible to use simple and cheap flat calibration test object instead of spatial one. To achieve the maximum result in camera calibration accuracy, use this method to tilt the chessboard at angles in the range of 30-40 degrees to the optical axis of the camera being calibrated.
\end{abstract}

\section{INTRODUCTION}

Although the calibration of digital cameras has been well studied and developed, research in this area continues and will continue because numerous results of calibrations of various cameras show the need to improve the accuracy of calibration. In the works (Thomas Luhman, et al. 2019, Mikhailov A. P., Chibunichev A. G. 2016, Barazzetti, L., et al. 2011, Chibunichev, A. G., et al., 2019, Knyaz, V. A. 2006, Knyaz, V. A. and Moshkantsev, P. V. 2019), you can find a description of the main methods of calibration of digital cameras used today. These methods are based on the application of both spatial and flat test objects, using various mathematical models of sensors (Luhmann T., et al., 2016, Remondino, F. and Fraser, C. S., 2006, Hannemose M., et al., 2019), including neural networks (Fakhri, S. A. and Fakhri, S. A., 2019). Recently, many researchers want to use a flat test object for camera calibration, since it is cheaper than a spatial object and more accessible (Choinowski, A., et al., 2019, Geiger A., et al., 2012, Grammatikopoulos, L., et al., 2019, Tan L., et al., 2017, Wohlfeil, J., et al., 2019). Basically, a chessboard is used as a flat test object in these works. This is natural, because it can be easily manufactured and there are quite a few methods for accurate automatic measurement of the coordinates of the chessboard nodes in the images. All these calibration methods are based mainly on repeatedly imaging the chessboard from different angles and then processing all the images together at the same time. As a result, not only the camera calibration parameters (focal length, principal point coordinates, and lens distortion) are determined, but also the external orientation elements of all images. In this paper, we propose a different approach for calibrating the camera by a flat test object.

\section{METHOD DESCRIPTION}

The essence of the method is as follows. The camera is mounted on a tripod and a series of images of a flat test object (for example, a chessboard) is taken at different distances and inclination angles of the test object (Fig.1).

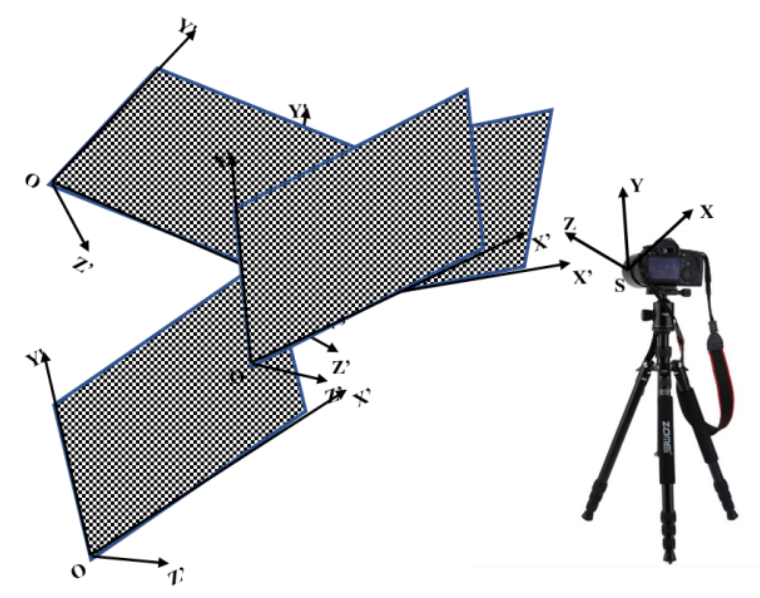

Figure 1. Imaging principle for calibrating the camera (the camera is stationary, but the chessboard moves and tilts)

Then all images are processed together, considering them as one image with fixed exterior orientation elements. In other words, exterior orientation elements of images are not defined, but set. The solution is based on the known collinearity equations, considering the exterior orientation elements of images as constant values and equal to zero: $\mathbf{X s}=\mathbf{Y} \mathbf{s}=\mathbf{Z s}=\boldsymbol{\omega}=\boldsymbol{\alpha}=\boldsymbol{\aleph}=\mathbf{0}$

\footnotetext{
* Corresponding author
} 


$$
\left.\begin{array}{l}
x_{0}-f \frac{X}{Z}-x+d_{x}=0 \\
y_{0}-f \frac{Y}{Z}-y+d_{y}=0
\end{array}\right\}
$$

Where

$$
\begin{aligned}
& \left(\begin{array}{l}
X \\
Y \\
Z
\end{array}\right)=\left(\begin{array}{c}
X_{0 i} \\
Y_{0 i} \\
Z_{0 i}
\end{array}\right)+A_{i}\left(\begin{array}{c}
X^{\prime} \\
Y^{\prime} \\
0
\end{array}\right) \\
& d_{x}=k_{1}\left(x-x_{0}\right)\left(\left(x-x_{0}\right)^{2}+\left(y-y_{0}\right)^{2}\right)+k_{2}\left(x-x_{0}\right)\left(\left(x-x_{0}\right)^{2}+\left(y-y_{0}\right)^{2}\right)^{2} \\
& d_{y}=k_{1}\left(y-y_{0}\right)\left(\left(x-x_{0}\right)^{2}+\left(y-y_{0}\right)^{2}\right)+k_{2}\left(y-y_{0}\right)\left(\left(x-x_{0}\right)^{2}+\left(y-y_{0}\right)^{2}\right)^{2}
\end{aligned}
$$

Here $\quad x, y=$ image coordinates

$\mathrm{X}^{\prime} \mathrm{Y}^{\prime}=$ coordinates of the flat test object (board) points in its OX'Y'Z' coordinate system

$\mathrm{f}, \mathrm{x}_{\mathrm{o}}, \mathrm{y}_{\mathrm{o}}, \mathrm{k}_{1}, \mathrm{k}_{2}=$ the unknowns. Interior orientation parameters of the camera (focal length, coordinates of the principal point, lens distortion coefficients)

$\mathrm{Xo}_{\mathrm{i}}, \mathrm{YO}_{\mathrm{i}}, \mathrm{ZO}_{\mathrm{i}}, \omega \mathrm{i}, \alpha_{\mathrm{i}}, \aleph_{\mathrm{i}}=$ the orientation elements of the $\mathrm{i}$-th flat test object (boards, $\mathrm{i}=2, \ldots \mathrm{n}$, where $\mathrm{n}$ is the number of boards) in the SXYZ coordinate system.

Since the test object has a flat structure, to avoid the uncertainty of determining the focal length at least 2 images of tilted boards should be used.

Equation (1) is none-linear and a linear approximation should be used to solve for unknowns. An experimental software was written in MATLAB system and consists of two parts. First one is doing preliminary operations. It reads photographs, performs measurements and prepare the data. Second one fulfils the calibration itself.

To start an iterative process a good approximation should be set for all unknowns. The initial value of the focal length of a camera lens is taken from EXIF data usually. First approximation for orientations of chessboards are determined by proposed method with interior parameters are set to approximation values. During this step the interior orientation parameters are not subject to change.

\section{RESULTS}

\subsection{Synthetic data}

Studies of the proposed calibration method were carried out using the simulated images. For this purpose, a chessboard was modeled with the size of $5 \times 5$ cells, in the coordinates of the nodes of which errors were introduced with an RMSE equal to $0.08 \mathrm{~mm}$. The camera was set with the following parameters: focal length $100 \mathrm{~mm}$, coordinates of the principal point $\mathrm{x}_{0}=\mathrm{y}_{0}=0$, no distortion. The error-free image coordinates were affected by errors with RMSE equal to $0.001 \mathrm{~mm}$. Chessboards were given different angles of inclination ranging from 5 to 75 degrees relative to the image plane. For each angle value, 4 boards were modeled with different angles of $\pm \alpha$ and $\pm \omega$. The results of the camera calibration are shown in table 1 and fig. 2. Here are the values RMSE camera calibration parameters obtained by deviations from the true values of the camera parameters. Each value in this table is determined as RMS from 100 trials.

\begin{tabular}{|l|l|l|l|l|l|}
\hline & $\begin{array}{l}\text { RMSE } \\
f \\
(\mathbf{m m})\end{array}$ & $\begin{array}{l}\text { RMSE } \\
\boldsymbol{x}_{\boldsymbol{o}} \\
(\mathbf{m m})\end{array}$ & $\begin{array}{l}\text { RMSE } \\
\boldsymbol{y}_{\boldsymbol{o}} \\
(\mathbf{m m})\end{array}$ & $\begin{array}{l}\text { RMSE } \\
\boldsymbol{k}_{\boldsymbol{1}}\end{array}$ & $\begin{array}{l}\boldsymbol{R M S E} \\
\boldsymbol{k}_{\mathbf{2}}\end{array}$ \\
\hline $\mathbf{5}^{\circ}$ & 1.178 & 0.080 & 0.089 & $5.85 E-09$ & $4.63 E-13$ \\
\hline $\mathbf{1 5}^{\circ}$ & 0.152 & 0.040 & 0.039 & $1.15 E-08$ & $5.80 E-13$ \\
\hline $\mathbf{2 5}^{\circ}$ & 0.057 & 0.029 & 0.029 & $1.60 E-08$ & $6.01 E-13$ \\
\hline $\mathbf{3 5}^{\circ}$ & 0.032 & 0.024 & 0.029 & $1.79 E-08$ & $5.41 E-13$ \\
\hline $\mathbf{4 5}^{\circ}$ & 0.025 & 0.025 & 0.033 & $1.89 E-08$ & $4.77 E-13$ \\
\hline $\mathbf{5 5}^{\circ}$ & 0.024 & 0.027 & 0.040 & $1.98 E-08$ & $3.89 E-13$ \\
\hline $\mathbf{6 5}^{\circ}$ & 0.022 & 0.027 & 0.043 & $2.17 E-08$ & $3.78 E-13$ \\
\hline $\mathbf{7 5}^{\circ}$ & 0.544 & 0.054 & 0.461 & $7.01 E-08$ & $1.00 E-12$ \\
\hline
\end{tabular}

Table 1 Estimation of the accuracy of determining the camera calibration parameters depending on the angle of inclination of the chessboard

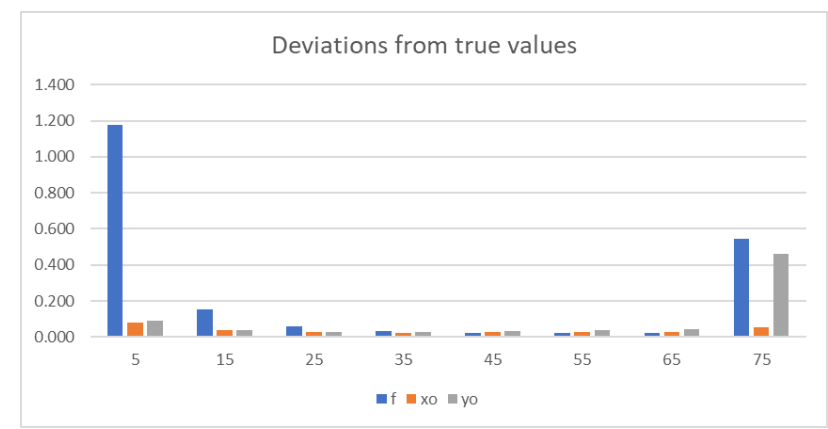

Figure 2. Evaluation of the accuracy of determining the camera calibration parameters depending on the angle of the chessboard

The results of experimental studies on synthetic data have shown that this calibration method has the right to exist. It is easily implemented, and gives positive results. To achieve the maximum result in camera calibration accuracy using this method the tilt the chessboards should be in the range of 30-40 degrees to the optical axis of the camera being calibrated.

\subsection{Real data}

The DigiCAM HASSELBLAD H3DII-39 with $35 \mathrm{~mm}$ focal length lens was used for experiment on real data (figure 3 ). This camera has a resolution of $7212 \times 5412$ pix, and the size of the matrix 39x37 mm.

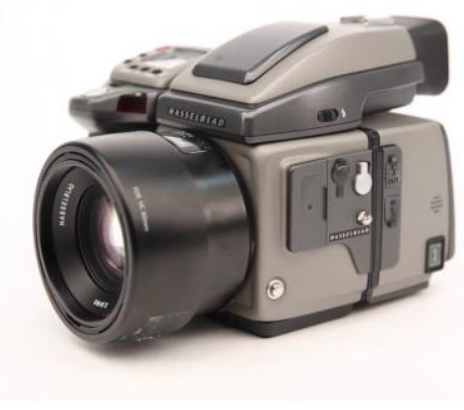

Figure 3. Digital camera HASSELBLAD H3DII-39 
For comparison with the proposed calibration method, the conventional calibration program was used. The conventional calibration software as well as test object were designed at the Photogrammetry Chair of MIIGAiK and show more than 20 years of reliable calibration process results. The test object is shown at figure 4 . There are 185 circular target points defined with $0.1 \mathrm{~mm}$ accuracy. The measurements of the image coordinates points are performed automatically calculating the geometric center of circular edge of the targets. The calibration software is based on collinearity equations extended by Brown polynomials for radial and tangential distortion definition. Typical number of images used for camera calibration is 4-6. In our case, 4 images were taken with the camera rotated 180 degrees and a small offset in the plan. All 4 images participated in the calibration of the camera using conventional technology. The results are shown in table 2 .

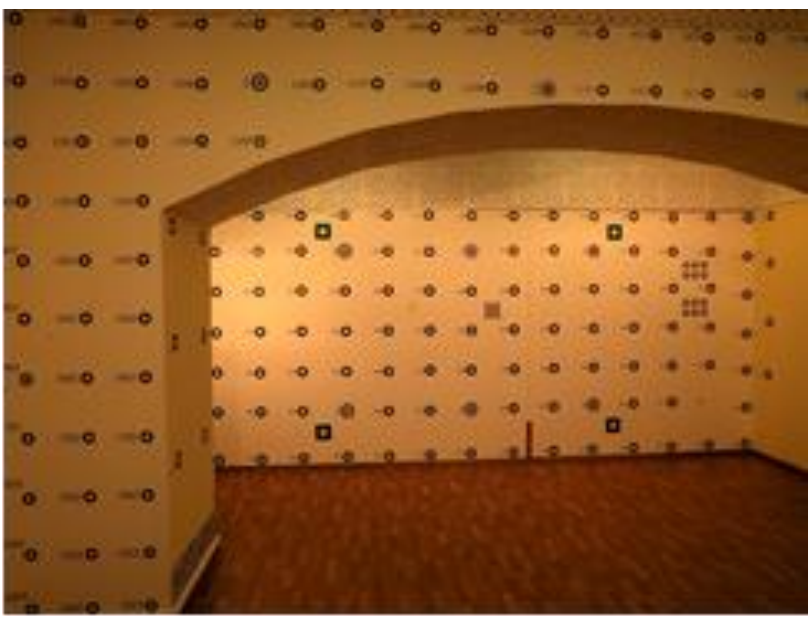

Figure 4. The calibration test object.

Figure 5 shows a chessboard survey to investigate the proposed camera calibration method. 10 images of the inclined chessboards have been used. The inclination varied from -40 up to +45 degrees in respect to the optical axis of the camera to be calibrated. The number of measured image points on each of chessboards was 96 . In figure 5 the measured points are shown in red circles. All measurements of the coordinates of the chessboard image points were performed automatically using standard MATLAB libraries. However, among these measurements, sometimes there are blunders. To blunder detection and exclude them from the adjustment, we used robust method (Chibunichev et al. 1992), in which each equation of corrections from the collinearity equations (1) is multiplied by the weight, which is calculated using the following formula:

$$
P_{i}=\left\{\begin{array}{cc}
1, & \text { if }\left|v_{i}\right| \leq 2 \mu \\
e^{-0.1\left(\frac{\left|v_{i}\right|}{\mu}\right)^{4},} & \text { if }\left|v_{i}\right| \leq 2 \mu \text { and } N \leq 3 \\
e^{-0.1\left(\frac{\left|v_{i}\right|}{\mu}\right)^{3}}, & \text { if }\left|v_{i}\right| \leq 2 \mu \text { and } N \triangleright 3
\end{array}\right.
$$

where $v_{i}$ is the discrepancy in the $i$ correction equation; $\mu$ is standard error calculated by $v_{i} ; \mathrm{N}$ is the iteration number. This approach has significantly improved the result of camera calibration.
Table 2 shows the results of camera calibration. We used only two radial distortion coefficients, since the other distortion coefficients do not improve accuracy for this camera. Here the root mean square error (RMSE) in determining the camera calibration parameters, obtained from an adjustment are shown in parentheses. As you can see from this table the accuracy of determining calibration parameters for the two methods is comparable.
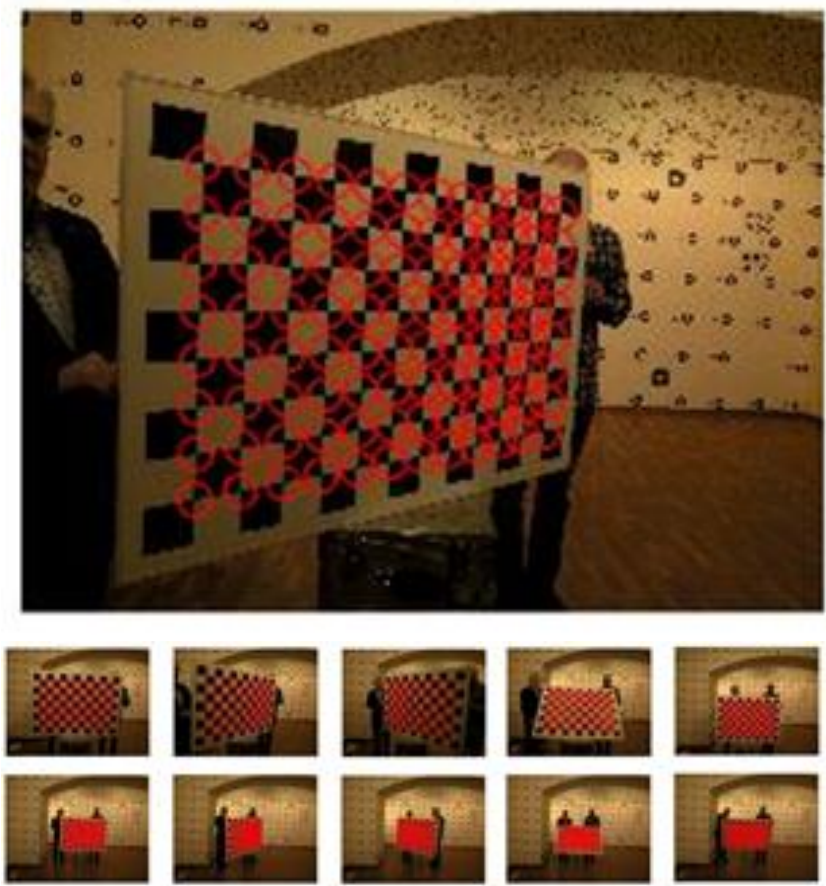

Figure 5. Examples of chessboards imaging

\begin{tabular}{|c|c|c|}
\hline Parameters & $\begin{array}{c}\text { Conventional } \\
\text { method }\end{array}$ & Proposed method \\
\hline $\begin{array}{c}\text { Sigma0 } \\
m m\end{array}$ & 0.002 & 0.002 \\
\hline $\begin{array}{c}f(R M S E), \\
m m\end{array}$ & $35.730(0.001)$ & $35.788(0.001)$ \\
\hline $\begin{array}{c}x_{o}(R M S E), \\
m m\end{array}$ & $0.009(0.001)$ & $0.081(0.001)$ \\
\hline $\begin{array}{c}y_{o}(R M S E), \\
m m\end{array}$ & $0.277(0.001)$ & $0.272(0.002)$ \\
\hline$k_{1}(R M S E)$ & $-7.3718 e-05$ & $-7.5239 e-$ \\
& $(1.0448 e-07)$ & $05(1.8257 e-07)$ \\
\hline$k_{2}(R M S E)$ & $5.3571 e-08$ & $5.9419 e-08$ \\
& $(1.1376 e-10)$ & $(5.6991 e-11)$ \\
\hline
\end{tabular}

Table 2. The calibration results for real images.

Figure 6 shows discrepancies between detected corner points and the re-projected ones with the estimated calibration parameters. From this figure, you can see that the main errors in re-projecting points to images after camera calibration are in the range of $-0.005 \mathrm{~mm}$ to $+0.005 \mathrm{~mm}$ for the two camera calibration methods. Moreover, the root mean square error for both methods are the same and equal to $0.002 \mathrm{~mm}$ (table 2). However, for the proposed calibration method, there are points that lie outside this interval. In the future, these points can be 
rejected, which should lead to an increase in the accuracy of camera calibration by the proposed method.

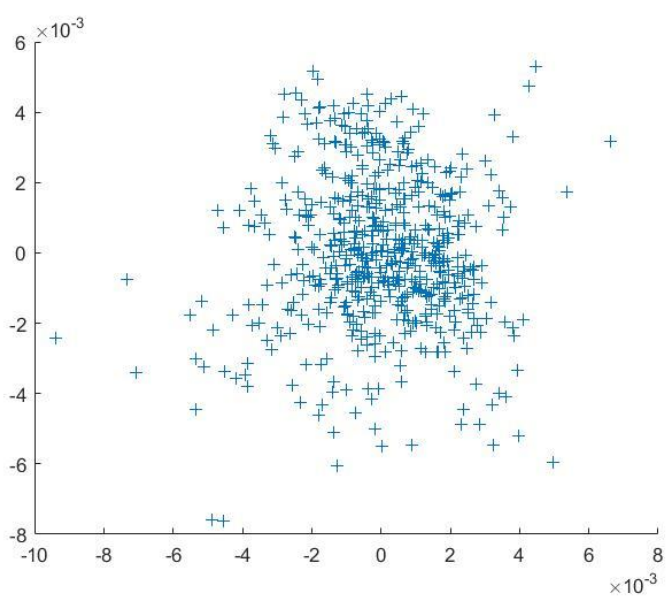

a)

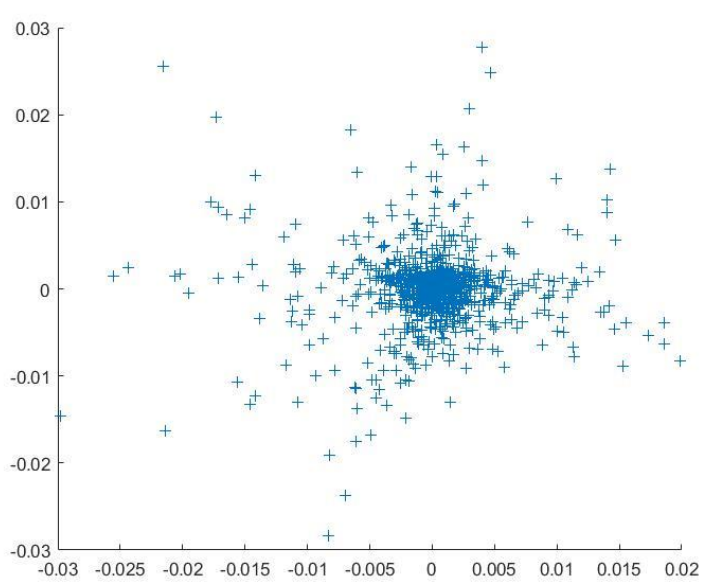

b)

Figure 6. Re-projection errors. a) for conventional method, b) for proposed method

The next experiment was to compare results of the definition of coordinates of points by photogrammetric processing of the stereopair using two sets of calibration parameters. To do this, a stereo pair of images of the spatial test object was obtained by the camera HASSELBLAD H3DII-39. Total measured in the stereopair points were 73. 52 target points were used as check points. The software is bundle adjustment procedure. Results are shown in the Table 3.

\begin{tabular}{|c|c|c|}
\hline RMSE, mm & $\begin{array}{c}\text { Conventional method } \\
\text { calibration used }\end{array}$ & $\begin{array}{c}\text { Proposed method } \\
\text { calibration used }\end{array}$ \\
\hline$X$ & 0.9 & 0.3 \\
\hline$Y$ & 0.4 & 0.4 \\
\hline$Z$ & 1.5 & 1.9 \\
\hline Planimetric & 1.0 & 0.5 \\
\hline Full vector & 1.8 & 1.9 \\
\hline
\end{tabular}

Table 3. RMSE of discrepancies at the check points

The results of experimental studies on real images have shown that proposed calibration method gives the comparable with conventional method accuracy. Thus, it is possible to use simple and cheap flat calibration test object instead of the spatial one.

\section{CONCLUSION}

Method for calibration of digital cameras based on the use of a flat test object is proposed. The main idea of the method is that a flat test object is shooting several times with a fixed camera while positions and orientations of the test object are changed. Then all images are processed together, considering them as one image with fixed exterior orientation elements. Experimental studies have shown sufficient efficiency of such calibration, which is easily implemented and gives positive results in comparison with the classical calibration of the camera using a spatial test object. To achieve the maximum result in camera calibration accuracy, use this method to tilt the chessboard at angles in the range of 30-40 degrees to the optical axis of the camera being calibrated.

In the future, we should continue experimental studies of the digital camera calibration method. Special attention should be paid to the number and location of the chessboards in space relative to the camera. In addition, the possibility of applying the method to calibrate different types of cameras should be explored.

\section{ACKNOWLEDGEMENTS}

The work was performed with the support by Grant 17-2904410 of Russian Foundation for Basic Research (RFBR).

\section{REFERENCES}

Barazzetti, L., Mussio, L., Remondino, F., and Scaioni, M. 2011. TARGETLESS CAMERA CALIBRATION, Int. Arch. Photogramm. Remote Sens. Spatial Inf. Sci., XXXVIII-5/W16, 335-342, https://doi.org/10.5194/isprsarchives-XXXVIII-5W16-335-2011.

Brown D.C. 1971. Close Range Camera Calibration. Photogrammetric Engineering 37 (8), pp. 855- 866.

Chibunichev A.G., Mikhailov A.P., Egorova O.I. 1992. Robust method for detection of gross errors in photogrammetric measurements. Izvestiya vusov "Geodeziyaiaerofotosyemka». Izvestia vuzov «Geodesy and Aerophotosurveying». (2): 93-97.

Chibunichev, A. G., Govorov, A. V., and Chernyshev, V. E. 2019. RESEARCH OF THE CAMERA CALIBRATION USING SERIES OF IMAGES WITH COMMON CENTER OF PROJECTION, Int. Arch. Photogramm. Remote Sens. Spatial Inf. Sci., XLII-2/W18, 19-22, https://doi.org/10.5194/isprsarchives-XLII-2-W18-19-2019.

Choinowski, A., Dahlke, D., Ernst, I., Pless, S., and Rettig, I. 2019. AUTOMATIC CALIBRATION AND COREGISTRATION FOR A STEREO CAMERA SYSTEM AND A THERMAL IMAGING SENSOR USING A CHESSBOARD, Int. Arch. Photogramm. Remote Sens. Spatial Inf. Sci., XLII-2/W13, 1631-1635, https://doi.org/10.5194/isprsarchives-XLII-2-W13-1631-2019.

Fakhri, S. A. and Fakhri, S. A. 2019. INVESTIGATING THE EFFECT OF PSO ALGORITHM ON REDUCING CONTROL POINTS IN CAMERA CALIBRATION, Int. Arch. Photogramm. Remote Sens. Spatial Inf. Sci., XLII-4/W18, 363 369, https://doi.org/10.5194/isprs-archives-XLII-4-W18-3632019. 
Geiger A., Moosmann F., Car Ö., Schuster B., 2012. Automatic camera and range sensor calibration using a single shot. IEEE International Conference on Robotics and Automation (ICRA), pp. 3936-3943.

Grammatikopoulos, L., Adam, K., Petsa, E., and Karras, G. 2019. CAMERA CALIBRATION USING MULTIPLE UNORDERED COPLANAR CHESSBOARDS, Int. Arch. Photogramm. Remote Sens. Spatial Inf. Sci., XLII2/W18, 59-66, https://doi.org/10.5194/isprs-archives-XLII-2W18-59-2019.

Hannemose M., Wilm J., Revall Frisvad J., 2019. Superaccurate camera calibration via inverse rendering. Modeling Aspects in Optical Metrology VII, Proc. SPIE, vol. 11057, no. 11057-40.

Knyaz, V. A. and Moshkantsev, P. V. 2019. JOINT GEOMETRIC CALIBRATION OF COLOR AND THERMAL CAMERAS FOR SYNCHRONIZED MULTIMODAL DATASET CREATING, Int. Arch. Photogramm. Remote Sens. Spatial Inf. Sci., XLII-2/W18, 79-84, https://doi.org/10.5194/isprs-archives-XLII-2-W18-79-2019.

Knyaz, V. A., 2006. Automated calibration technique for photogrammetric system based on a multi-media projector and a ccd camera. ISPRS - International Archives of the Photogramme- try, Remote Sensing and Spatial Information Sciences XXXVI-5, pp. 1-5.

Luhmann T., Fraser C., Maas H.-G., 2016. Sensor modelling and camera calibration for close-range photogrammetry. ISPRS Journal of Photogrammetry \& Remote Sensing, 115, pp. 37-46

Mikhaylov A.P., Chibunichev A.G. 2016. Photogrammetry: Textbook for universities/Under general edition A.G. Chibunichev. Moscow: MIIGaik.

Remondino, F. and Fraser, C. S., 2006. Digital camera calibration methods: considerations and comparisons. International Archives of Photogrammetry, Remote Sensing and Spatial Information Sciences, Vol. XXXVI, Part 5, pp. 266-272.

Tan L., Wang Y., Yu H., Zhu J., 2017. Automatic camera calibration using active displays of a virtual pattern. Sensors, 17,685 .

Thomas Luhman, 2019. Stuart Robson, Stephen Kyle, Jan Boehm. Close-Range Photogrammetry and 3D Imaging. De Grueter, Berlin/Boston.

Wohlfeil, J., Grießbach, D., Ernst, I., Baumbach, D., and Dahlke, D. 2019. AUTOMATIC CAMERA SYSTEM CALIBRATION WITH A CHESSBOARD ENABLING FULL IMAGE COVERAGE, Int. Arch. Photogramm. Remote Sens. Spatial Inf. Sci., XLII-2/W13, 1715-1722, https://doi.org/10.5194/isprs-archives-XLII-2-W13-1715-2019. 